\title{
Potential and Hypothesized Determinants of the Positive and Negative Effects as a Result of Pornography Use in Dyadic Relationships
}

\author{
Isha Leibel ${ }^{1}$
}

\begin{abstract}
In this literature review, I will be looking at the different potential and hypnotized determinants of positive and negative effects pornography has on dyadic relationships. Specifically, I recognize three of the most frequently mentioned and studied areas of concern that are discussed in the body of literature. These three areas are: attitudes towards pornography, partnered, solitary and/or non-existent pornography use, and frequency of pornography use. A plethora of mixed effects are found, both positive and negative, and suggestions for future research is made. Theses suggestions include three additional areas to focus on, which include: content of pornography, transparency of pornography use between partners, a more in-depth look at different relationship commitment levels, and how all three of these relate to positive and negative impacts on a dyadic relationship.
\end{abstract}

\footnotetext{
${ }^{1}$ MacEwan University
} 
Leibel

\section{Introduction}

Pornography is empirically established as being one of the most prolific sources of sexual socialization in North America, for both men and women alike (Ezzell, Johnson, Bridges, \& Sun, 2020; Fritz \& Paul, 2017; Parvez, 2006; Simon \& Daneback, 2013; Sun, Bridges, Wosnitzer, Scharrer, \& Liberman, 2008). Not only do all sexes engage in watching pornography, but also a variety of different relationship statuses as well. In fact, recent studies have shown that about $71 \%$ to $92 \%$ of men, and $34 \%$ to $83 \%$ of women in committed heterosexual relationships engage in watching pornography (Kohut, Fisher, \& Campbell, 2017; Willoughby, Carroll, Busby, \& Brown, 2016). For some individuals, these socialized pornographic sexual scripts come to influence their in-person partnered sexual experiences (Carroll, Busby, Willoughby, \& Brown, 2017; Leonhardt, Spencer, Butler, \& Theobald, 2018; Miller, McBain, Li, \& Raggatt, 2019; Vaillancourt-Morel, Rosen, Willoughby, Leonhardt, \& Bergeron; 2020). Studies show that pornography can have both beneficial and detrimental effects for both partners in a dyadic relationship, and that these effects tend to vary based on a number of different circumstances (Ashton, McDonald, \& Kirkman, 2020; Kohut, Balzarini, Fisher, \& Campbell, 2018).

Contemporarily speaking, most of the research done on this topic is no longer looking at if pornography affects relationships, but rather how it affects relationships. To build upon these previous studies, I will conduct a contemporary literature analysis on various studies that discuss the intersections of pornography and committed intimate relationships. From there, I will discuss three of the most commonly found, or hypothesized, potential determinants of both positive and negative effects of the use of pornography in dyadic relationships. In line with the similarity/attraction theory, I hypothesize that individuals will experience lower relationship satisfaction when the partners in the relationship have differing patterns of pornography usage. Despite the growing acceptance and normalization of pornography, I also hypothesize that the intersection of pornography and dyadic relationships will be the cause of more negative impacts than positive impacts on the relationship itself. Although I believe society has progressed greatly through many sex positivist movements (Mosher, 2017), I do not think this has fully extended to the realm of pornography quite yet. Lastly, from a queer theoretical lens, I am curious about the extent in which queer couples are studied in comparison to heterosexual couples; as such, I hypothesize that although less prominent, there will be some LGBTQ+ focus in the research on how pornography and dyadic relationships positively and negatively coexist.

The parameters surrounding what pornography is, and what is considered to be the 'use' of pornography, has varied significantly throughout the years of empirical research on pornography (Kohut, Balzarini, Fisher, Grubbs, Campbell, L., \& Prause, 2020). To maintain congruency between the texts I examine, I will be basing my research off texts that use largely similar definitions of pornography to the following one established in Kohut et al.'s recent study on the topic:

Pornography use is a common but stigmatized behavior, in which one or more people intentionally expose themselves to representations of nudity which may or may not include depictions of sexual behavior, or who seek out, create, modify, exchange, or store such materials. Pornography use can involve one or more types 
of online and offline materials, and can occur in a variety of locational, social, and behavioral contexts. The extent and nature of such behaviors are regulated and shaped by a combination of personal and social hedonic motives, as well as other individual differences and environmental factors. Pornography use can evoke immediate sexual and affective responses, and may contribute to more lasting cognitive, affective, and behavioral changes. ${ }^{2}$

Although the definition of pornography may slightly vary between each text I will examine, the overarching themes of what pornography is, and what is considered as engaging in pornography, remain consistent across the board. As discussed in Kohut et al.'s research, it is paramount to maintain a consistent definition of this diversely understood topic to produce reliable and comparable data between empirical studies (Kohut, et al., 2020). Therefore, for the context of this paper, I will be using the above definition of pornography to examine and collect data from each text, unless otherwise specified.

Among the several articles I reviewed, I have found three significant determined and/or hypothesized potential determinants of both positive and negative effects as a result of pornography use in dyadic relationships. These three potential determinants have been chosen based on the relevancy to the topic and/or frequency in which it was discussed in each paper: attitude toward pornography use, use of pornography (together, alone, or not at all), and frequency of pornography use. I conclude by bringing forth three additional potential determinants, which were mentioned throughout, but not largely expanded upon, that I suggest should be considered for future research: content of pornography, transparency of pornography use, and degree of relationship commitment.

\section{Attitudes Toward Pornography Use}

Pornography, and how one perceives the use of it, is a debated topic across all relationship types (Carroll, Busby, Willoughby, \& Brown, 2017). Studies have shown that, for individuals in dyadic relationships, attitudes on pornography use whilst in relationships ranges anywhere from believing it has a positive effect on the relationship, it has no effect on the relationship, to it is damaging to the relationship. In particular, Carroll et al.'s research found that regardless of one's perception of pornography use, it is clear that pornography use is not viewed as merely "acceptable or unacceptable", but rather it is enmeshed with a person's own sexual values, relationship sexual behaviour, relationship scripts, as well as boundaries (2017). Therefore, possibly unsurprisingly, there are a plethora of varying attitudes towards pornography use, which in turn leads to a variety of both positive and negative outcomes.

\footnotetext{
${ }^{2}$ Kohut, Balzarini, Fisher, Grubbs, Campbell \& Prause, 2020
} 
Leibel

\section{Positive Attitudes Toward Pornography Use}

According to contemporary studies, a large part of the population holds a favourable attitude towards to use of pornography whilst in a relationship (Ashton, McDonald, \& Kirkman, 2020; Maas, Vasilenko, \& Willoughby, 2018; Kohut, Fisher, \& Campbell, 2017). Furthermore, it has also been determined that gender plays a major factor in one's acceptance of pornography use, and in turn the positive impact it had on their relationship satisfaction (Maas et. al., 2018). For instance, in Maas et al.'s recent study it was found that men who are more accepting of pornography have higher positive associations with their own personal relationship satisfaction than women who are accepting of partnered pornography use (2018). Furthermore, a recent study, that focused specifically on the female experience and their attitudes toward pornography use in dyadic relationships, found that there were numerous individuals that held positive attitudes toward pornography, and in turn also experienced positive relational effects (Ashton et al., 2020).

The women in the study that held positive attitudes toward pornography were found to have four overarching opinions in support of pornography: pornography mediates intimacy, pornography is used for relaxation and therefore is not infidelity, one's right to sexual freedom, and the fact that sexual freedom is paramount (Ashton et al., 2020). For those who believed that pornography mediated intimacy, they described pornography use as in integrated component of partnered sex, which gave light to new sexual activities or a shared source of arousal (Ashton et al., 2020). That being said, it is important to note that this perspective was largely held within the context of shared pornography use, rather than solitary pornography use. Even still, when considering the many women's perspective that pornography use is key in relaxation and sexual freedom, these points were in consideration to both solitary and shared pornography use (Ashton et al., 2020).

All of the positive attitudes found in Ashton et al.'s study were correlated to positive relationship effects such as enhancing partnered sexual experience and intimacy, facilitating dialogue, excitement, and the encouragement of fantasies (2020). Kohut et al. similarly found that a large number of partnered individuals held the opinion that pornography use by individuals in dyadic relationships is a positive behaviour that is associated with positive relationship effects (2017). Although one of the largest findings was generally neural, stating that individuals felt that pornography use in dyadic relationships have no negative impact on the relationship itself, other actively positive impacts were also listed (Kohut et al., 2017). One of the positive impacts partnered individuals noted was that pornography was a good source of information (Kohut et al., 2017). As such, they also stated that due to this source of information, their experience of sexual experimentation in their relationship was positively affected by normalizing sexual variety and broadening their sexual repertoire (Kohut et al., 2017). Other aspects, such as sexual communication and sexual comfort and acceptance of user's sexual behaviour was also positively affected by those who viewed pornography positively (Kohut et al., 2017). Lastly, those with positive attitudes toward pornography use in dyadic relationships also noted that pornography provided an alternative and/or additional outlet for sexual satisfaction. This was mentioned as a positive aspect as it gave each partner the ability to pursue their desired sexual desire, without impeding on their other's lack of sexual interest or availability at the time (Kohut et al., 2017). 
This study in particular found many individuals that both held positive attitudes toward pornography use, as well as many noted positive effects on one's relationship.

\section{Negative Attitudes Toward Pornography Use}

Within the above studies, there was also data supporting the fact that many other individuals hold negative perspectives toward pornography, which, more often then not, lead to negative outcomes within the relationship (Ashton et al., 2020; Carroll et al., 2017; Kohut et al., 2017; Maas et al, 2018). In Carroll et al.'s study, it was found that as much as one-half of women in romantic relationships disapprove of pornography use within dyadic relationships, and nearly one-third of married and engaged women view this behaviour as infidelity (2017). Interestingly, one-fifth of partners found pornography use to be acceptable under the condition that is was viewed together as a couple (Carroll et al., 2017). It appears in this study that the issue partnered individuals had with pornography was more to do with the context in which it was watched, rather than the pornography itself. On the other hand, Maas et al.'s findings on those who are not accepting of pornography use within a dyadic relationship, for both men and women alike, believe that more pornography use is associated with a lessened relationship satisfaction. Moreover, the negative effect on relationship satisfaction was intensified for women, who held apposing views to pornography use within a dyadic partnership, in comparison to men (Maas et al., 2018). Clearly, for this data set, the viewing of pornography was enough cause for concern.

In regard to the findings by Ashton et al., there were some women who disagreed with the overarching opinions noted by the researchers, as well as provided additional negatively associated opinions on pornography use within dyadic relationships (2020). In particular, there were some women who did not feel as though pornography mediated intimacy, due to the two partners' differing tastes in pornography (Ashton et al., 2020). Furthermore, when discussing their partner's solitary pornography use, the idea that 'men are the gatekeepers of intimacy' was brought forth (Ashton et al., 2020). By this, the women in the study explained that because their partner can access sexual satisfaction outside of their partnered sexual relationship, through pornography use, their partner's engagement with pornography was viewed as a threat to the relationship by withholding or disrupting the couples' intimacy (Ashton et al., 2020). Because some women stated that they felt sexual desire was an expression of emotional intimacy, they were especially hurt when their partner decided to engage in their own sexual desire elsewhere. These perspectives also relate to another overarching theme that was found, which is the idea that pornography use within a committed intimate relationship is viewed as infidelity (Ashton et al., 2020). This was especially true for women in the data set that were affiliated with a religious practice (Ashton et al., 2020). Lastly, because some of the women viewed pornography as a competing source of sexual desire and intimacy, they felt the need to embody a similar attractiveness and sexual desirability to what is shown in the pornography, which lead them to objectifying themselves to achieve this: "Is my body good enough? Is it going to be enough to satisfy my partner?” (Ashton et al., 2020). 
Alongside the previously mentioned positive effects in Kohut et al.'s study, there were negative ones that were noted as well (2017). Individuals reported that they felt pornography use within dyadic couples can lead to decreased feelings of self-worth and increased feelings of personal insecurity, jealously, and/or envy (Kohut et al., 2017). It was also noted by the researchers that a decrease in interest in sex was a negative outcome from pornography use within dyadic relationships (Kohut et al., 2017). Last of all, many individuals felt that pornography use had the potential to cause unrealistic expectations of one's partner in their sexual relations, specifically regarding one's appearance, like and dislikes, and performance (Kohut et al., 2017). Concerns regarding unrealistic expectations were found to be the most common theme that represented negative effects from pornography use within a relationship (Kohut et al., 2017).

\section{Pornography Use: Alone, Together or Not at All}

Not only does one's view about pornography use vary, but the context in which it is engaged with by individuals in dyadic relationships can exist in a variety of ways; partners can engage with pornography together, otherwise known as shared pornography use, they can engage with it alone, one partner can engage with it whilst the other doesn't engage with it at all, and sometimes neither partner engages with pornography at all (Carroll et al., 2017; Fritz \& Paul, 2017; Kohut et al., 2017; Kohut, Balzarini, Fisher, \& Campbell, 2018; Maddox, Rhoades, \& Markman, 2011; Willoughby \& Leonhardt, 2020). For some studies, the context in which partners use pornography whilst in dyadic relationships proves to be quite gendered, suggesting men most commonly watch pornography alone whereas women most commonly watch it with their partner (Fritz \& Paul, 2017; Carroll et al., 2017; Maddox et al., 2011). Alternatively, Willoughby et al., found that largely speaking both men and women largely use pornography alone, rather than with their partner (2020). It will be interesting for researchers to compare these results again in the future, when more studies come out looking at the gendered differences between alone and shared pornography use within dyadic relationships.

\section{Positive Effects of Pornography Use Context}

Among the reviewed literature there were four main findings on positive effects of pornography use within dyadic relationships, based on the context in which it was used: greater sexual communication, greater closeness, higher sexual satisfaction, and higher dyadic sexual desire (Kohut et al., 2018; Vaillancourt-Morel, Rosen, Willoughby, Leonhardt, \& Bregeron, 2020; Willoughby et al., 2020). In Kohut's 2018 study is was shown that partners who used pornography together reported having greater closeness and higher levels of open sexual communication, in comparison to those who did not engage in pornography viewing together. Interestingly, concordant non-users of pornography reported similarly high levels of sexual open communication and closeness (Kohut et al., 2018). Kohut suggests that these findings are congruent with previous 
academic findings on similarly and attraction, which has been well established over the years (2018). Similarly, Willoughby et al.'s recent study found that specifically shared pornography use was associated with positive relationship effects, such as higher reported sexual satisfaction within the relationship (2020). Lastly, Vaillancourt-Morel et al. found that even for solitary pornography use, on days when a woman used pornography, the woman and her partner both reported higher dyadic sexual desire, regardless if their partner was a man or woman (2020). This study was particularly interesting in nature is it accounted for both same and mixed sexed couples, which was not common among the other primarily heterosexual focuses.

\section{Negative Effects of Pornography Use Context}

On the other hand, there were also numerous negative effects that were a result of different contexts in which pornography was used within dyadic relationships (Kohut et al., 2018; Parvez, 2006; Willoughby et al., 2020; Vaillancourt-Morel et al, 2020). In regard to when pornography use is done together, some women reported feelings of jealously and discomfort with their partner when they felt their partner was paying more attention to the pornography than to themselves (Parvez, 2006). When looking at solitary pornography use within dyadic relationships, Kohut et al. found that participants who were discordant in solitary pornography use had stated that they experienced more inhibited sexual communication and lower closeness with their partner (2018). In addition to this, Willoughby et al. found that for women in heterosexual partnerships in particular were negatively affected by their male counterpart's pornography use (2020). Their male partner's pornography use was associated with less male and female relationship satisfaction, lower male positive communication, and lower female sexual desire (Willoughby et al., 2020). Similarly, Vaillancourt-Morel found that men's pornography use in dyadic relationships negatively affected their partner's sexual desire and overall partnered sexual activity (2020). These results were studied among both mixed and same sex couples, but only men coupled with women experienced the mentioned negative effects on their partner.

\section{Pornography Use: Frequency}

Over the years in academia research, one of the most commonly discussed gender differentiation regarding pornography use is the frequency in which it occurs for both men and women (Borgogna, Lathan, \& Mitchell, 2018; Carroll et al., 2017; Kohut et al., 2017; Kohut et al., 2018; Miller et al., 2019; Maas et al., 2018). For as long as pornography has been studied, males have empirically been proven to engage in pornography viewing more than women and accordingly to recent research this remains true (Willoughby, et al., 2020; Kohut et al., 2017; Vaillancourt-Morel et al., 2020). Specifically, Willoughby et al. found that $81.5 \%$ of men reported pornography use in the last year compared to only $67.2 \%$ of women (2020); Kohut et al. found that 
male participants use pornography significantly more frequently than their female counterparts (34 times a week in comparison to 1-3 times a month) (2017); Carroll et al. found that casually dating men are 42 times more likely to view pornography than casually dating women (2017). Overall, when looking at both men and women together, Miller et al. found that $70.7 \%$ of their sample had viewed pornography in the last 6 months, with the median frequency of engaging with pornography was 1-2 per week. In short, both men and women engage in pornography, but the gender gap between the two still exists today.

\section{Effects of Pornography Use Frequency}

Some studies have shown that in some cases higher frequency solitary pornography use has been found to be associated with a number of positive relationship effects (Miller et al, 2019; Kohut et al., 2018; Willoughby et al., 2020; Vaillancourt-Morel et al., 2020). The positive effects that have come from higher frequency pornography use includes positive indirect effects on sexual satisfaction (Miller et al, 2019), high levels of openness in sexual communication and closeness (Kohut, et al., 2018), higher male and female sexual desire, for the pornography user themselves, (Willoughby et al., 2020; Vaillancourt-Morel, 2020), and higher odds of partnered sexual activity Vaillancourt-Morel et al., 2020). That being said, the list for negative effects on relationships is longer and therefore also worth noting.

In almost complete opposition to the previously mentioned studies, higher frequency rates of pornography use within dyadic relationships has been empirically shown to result in decreased relationship satisfaction (Maas et al., 2018); lower female sexual desire, when their partner engages in high frequency pornography use (Willoughby et al., 2020); female body iage and relationships dissatisfaction, when used in excess by females themselves (Borgogna et al., 2018); and overall sexual dissatisfaction and a greater preference for porn-like sex (Miller, 2019). Although a greater liking for porn-like sex doesn't result in an inherently negative effects on dyadic relationships, due to the high objectivity, lack of sexual agency, and common occurrence of violence, primarily all directed toward women, that occurs in mainstream pornography, one can concur that the male use of pornography, whilst in a committed dyadic heterosexual relationship, would lead to a highly likelihood of negative effects for the his female counterpart (Fritz et al., 2017; Maas et al., 2018; Miller et al., 2019).

\section{Conclusion}

Given the largely varying results from all of the reviewed literature, there are few overarching conclusions that we are able to come to. First and foremost, despite intensive research on the topic, for every article that defends one point, there are a variety of other articles that report the exact opposite. After reviewing the literature, I have found a few reasons for why this may be. As suggested by numerous of the texts, pornography is still a largely understudied field of research that requires much more attention in the field of academia (Borgogna et al., 2018; Carroll et al; 2017). Furthermore, although providing a concrete definition at the beginning of this piece, the 
definition of pornography continues to vary from study to study, and therefore provides an invalid platform of measurement. Therefore, it is suggested by the researcher of this article, as well as numerous other researchers within other articles, that the definition of pornography and pornography use needs to be concretized before moving forward with in-depth analysis of it's effects on individuals and their relationships (Carroll et al., 2017; Kohut, Balzarini, Fisher, Grubbs, Campbell, \& Prause, 2020; Maas et al., 2018; Vaillancourt-Morel, 2020). In addition to this, despite our hypothesis that LGBTQ+ relationships would be more equally represented in contemporary research, this was disappointingly not the case. I propose there to be future studies that employ more inclusive and broadly reaching research on all sexualities and sexual identities.

Lastly, as determined within each category of exploration, the gender gap of pornography use, frequency, and attitudes remains heavily in place. With society progressing, I wonder why this is and suggest future research should explore this more in-depth. Although there was brief mentioning to these areas of interest throughout this literature analysis, I believe future research needs to pay closer attention to the topics of content of pornography, transparency of pornography use between partners, and degree of relationship commitment, and how all of these come to positively or negatively effect one's relationship. Although commitment level was addressed more in-depth, in comparison to the two other topics, I feel as though the direct effects on relationship satisfaction, in particular, still has room for improvement. 


\section{References}

Ashton, S., McDonald, K., \& Kirkman, M. (2020). Pornography and sexual relationships: Discursive challenges for young women. Feminism \& Psychology, 30(4), 489-507. http://doi.org/10.1177/0959353520918164

Borgogna, N. C., Lathan, E. C., \& Mitchell, A. (2018). Is women's problematic pornography viewing related to body image or relationship satisfaction? Sexual Addiction \& Compulsivity, 25(4), 345-366. http://doi.org/10.1080/10720162.2018.1532360

Campbell, L., \& Kohut, T. (2017). The use and effects of pornography in romantic relationships. Current Opinion in Psychology, 13, 6-10. http://doi.org/10.1016/j.copsyc.2016.03.004

Carroll, J. S., Busby, D. M., Willoughby, B.J., \& Brown, C. C. (2017). The porn gap:

Differences in men's and women's pornography patterns in couple relationships. Journal of Couple \& Relationship Therapy, 16(2), 146-163. http://doi.org/10.1080/15332691.2016.1238796

Ezzell, M. B., Johnson, J. S., Bridges, A. J., \& Sun, C. F. (2020). I (dis)like that: Gender, pornography, and liking sex. Journal of Sex \& Marital Therapy, 46(5), 460-473. https://doi.org/10.1080/0092623X.2020.1758860

Fritz, N., \& Paul, B. (2017). From orgasms to spanking: A content analysis of the agentic and objectifying sexual scripts in feminist, for women, and mainstream pornography. Sex Roles, 77(9-10), 639-652. http://doi.org/10.1007/s11199-017-0759-6

Kohut, T., Fisher, W. A., \& Campbell, L. (2017). Perceived effects of pornography on the couple relationship: Initial findings of open-ended, participant-informed, "bottom-up" research. Archives of Sexual Behavior, 46(2), 585-602. http://doi.org/10.1007/s10508-016-0783-6

Kohut, T., Balzarini, R. N., Fisher, W. A., \& Campbell, L. (2018). Pornography's associations with open sexual communication and relationship closeness wary as a function of dyadic patterns of pornography use within heterosexual relationships. Journal of Social and Personal Relationships, 35(4), 655-676. http://doi.org/10.1177/0265407517743096 10.1177/0265407517743096

Kohut, T., Balzarini, R. N., Fisher, W. A., Grubbs, J. B., Campbell, L., \& Prause, N. (2020). Surveying Pornography Use: A Shaky Science Resting on Poor Measurement Foundations. Journal of Sex Research, 57(6), 722-742. http://doi.org/10.1080/00224499.2019.1695244

Lambert, N. M., Negash S., Stillman T. F., Olmstead S.B., \& Fincham, F. D. (2012). A love that doesn't last: Pornography consumption and weakened commitment to one's romantic partner. Journal of Social and Clinical Psychology, 31(4), 410-438. http://doi.org/10.1521/jscp.2012.31.4.410

Leonhardt, N. D., Spencer, T. J., Butler, M. H., \& Theobald, A. C. (2019). An organizational framework for sexual media's influence on short-term versus long-term sexual quality. Archives of Sexual Behavior, 48(8), 2233-2249. http://doi.org/10.1007/s10508-018-12094

Maas, M. K., Vasilenko, S. A., \& Willoughby, B. J. (2018). A dyadic approach to pornography use and relationship satisfaction among heterosexual couples: The role of pornography acceptance and anxious attachment. Journal of Sex Research, 55(6), 772-782. http://doi.org/10.1080/00224499.2018.1440281 
Maddox, A. M., Rhoades, G. K., \& Markman, H. J. (2011). Viewing sexually-explicit materials alone or together: Associations with relationship quality. Archives of Sexual Behaviour, 40(2), 441-448. http://doi.org/10.1007/s10508-009-9585-4

Miller, D. J., McBain, K. A., Li, W. W., \& Raggatt, P. T. F. (2019). Pornography, preference for porn-like sex, masturbation, and men's sexual and relationship satisfaction. Personal Relationships, 26(1), 93-113. http://doi.org/10.1111/pere.12267

Minarcik, J., \& Wetterneck, C. T., Short, M.B. (2016). The effects of sexually explicit material use on romantic relationship dynamic. Journal of Behavioral Addictions, 5(4), 700-707. http://doi.org/10.1556/2006.5.2016.078

Mosher, C. M. (2017). Historical perspectives of sex positivity: Contributing to a new paradigm within counseling psychology. Counseling Psychologist, 45(4), 487-503. http://doi.org/10.1177/0011000017713755

Parvez, Z. F. (2006). The labor of pleasure: How perceptions of emotional labor impact women's enjoyment of pornography. Gender and Society, 20(5), 605-631. http://doi.org/10.1177/0891243206291109

Simon, L., \& Daneback, K. (2013). Adolescents' use of the internet for sex education: A thematic and critical review of the literature. International Journal of Sexual Health, 25(4), 305-319. http://doi.org/ 10.1080/19317611.2013.823899

Sun, C., Bridges, A., Wosnitzer, R., Scharrer, E., \& Liberman, R. (2008). A comparison of male and female directors in popular pornography: What happens when women are at the helm? Psychology of Women Quarterly, 32(3), 312-325.

Vaillancourt-Morel, M-P., Daspe, M-E., Charbonneau-Lefebvre, V., Bossio, M., \& Bergeron, S. (2019). Pornography use in adult mixed-sex romantic relationships: Context and correlates. Current Sexual Health Reports, 11(1), 35-43. http://doi.org/10.1007/s11930019-00190-2

Vaillancourt-Morel, M-P., Rosen, N. O., Willoughby, B. J., Leonhardt, N.D., \& Bergeron, S. (2020). Pornography use and romantic relationships: A dyadic daily diary study. Journal of Social \& Personal Relationships, 37(10-11), 2802-2821. http://doi.org/ 10.1177/0265407520940048

Willoughby, B. J., Carroll, J. S., Busby, D. M., \& Brown, C. C. (2016). Differences in pornography use among couples: Associations with satisfaction, stability, and relationship processes. Archives of Sexual Behaviour, 45, 145-258. http://doi.org/10.1007/s10508-015-0562-9

Willoughby, B.J., \& Leonhardt, N.D. (2020). Behind closed doors: Individual and joint pornography use among romantic couples. Journal of Sex Research. 57(1), 77-91. http://doi.org/10.1080/00224499.2018.1541440 